\title{
INFANTILE BERI-BERI IN SINGAPORE DURING THE LATTER PART OF THE JAPANESE OCCUPATION
}

BY

\author{
G. HARIDAS, L.M.S. (Singapore), M.R.C.P.
}

(From the Kandang Kerbau Hospital, Singapore)

The problems presented by infantile beri-beri in Singapore during the years 1944 and 1945 , up to the arrival of the liberating British forces on September 5,1945 , were of a different character from those obtaining in peace-time. They were: (a) apathy of the authorities; (b) lack of medicines; (c) lack of essential foods; and (d) shortage of milk or milk substitutes. For purpose of actual description and discussion, cases will be dealt with as they occurred among children admitted to the Japanese civilian hospital called the 'Chuo Byoin,' at Kandang Kerbau, Singapore. In pre-war days this was a maternity hospital. After Japan's declaration of war with the Allies on December 8, 1941, provision was made for the admission and treatment of casualty cases. After the fall of Singapore on February 15, 1942, the Japanese converted it into a civilian general hospital and called it the "Chuo Byoin.' In addition to maternity beds, they provided accommodation for the treatment of adult male and female medical and surgical cases, gynaecological cases, and sick children. There were 349 beds for adults, male and female (excluding maternity beds) and 12 beds for sick children. Table 1 shows the percentage mortality in children suffering from beri-beri, compared with the total mortality for children and for adults.

Some pre-war figures of infantile beri-beri cases admitted into the Children's wards, General Hospital, Singapore, are given in table 2. The Children's wards accommodated 120 patients of under six years old. My figures during 1936 and those of Cecily D. Williams between August, 1937, and July, 1938, are as follows:

Figures of infantile mortality and of infantile beri-beri deaths respectively for the island of Singapore for the years 1938 to 1944 obtained from the Registrar-General of Births and Deaths, are given in table 3. These figures include cases treated at all Government and Municipal hospitals and dispensaries and by private practitioners. Figures
TABLE 1

\begin{tabular}{|c|c|c|c|}
\hline$\cdot$ & $\underset{\text { missions }}{\text { Ad- }}$ & Deaths & $\begin{array}{l}\text { Per- } \\
\text { centage } \\
\text { mortal- } \\
\text { ity }\end{array}$ \\
\hline $\begin{array}{l}\text { Sick children } \\
\text { Infantile beri-beri } \\
\text { Adult in-patients }\end{array}$ & $\begin{array}{r}854 \\
139 \\
9,490\end{array}$ & $\begin{array}{r}392 \\
77 \\
1,592\end{array}$ & $\begin{array}{l}45 \cdot 90 \\
55 \cdot 41 \\
16 \cdot 77\end{array}$ \\
\hline
\end{tabular}

TABLE 2

\begin{tabular}{c|c|c|c|c}
\hline & & $\begin{array}{c}\text { Ad- } \\
\text { missions }\end{array}$ & Deaths & $\begin{array}{c}\text { Percentage } \\
\text { mortality }\end{array}$ \\
\hline $\begin{array}{c}\text { Infan- } \\
\text { tile } \\
\text { beri- } \\
\text { beri }\end{array}$ & $\begin{array}{c}1936 \\
\begin{array}{c}\text { Aug. 1937 } \\
\text { to July } \\
1938\end{array}\end{array}$ & 316 & 146 & $46 \cdot 20$ \\
\hline
\end{tabular}

TABLE 3

\begin{tabular}{c|c|c}
\hline & $\begin{array}{c}\text { Infantile } \\
\text { mortality }\end{array}$ & $\begin{array}{c}\text { Infantile } \\
\text { beri-beri }\end{array}$ \\
\hline 1938 & 5,065 & 25 \\
1939 & 4,516 & 259 \\
1940 & 4,819 & 151 \\
1941 & Not known & 131 \\
1942 & 7,340 & 97 \\
1943 & 5,052 & 232 \\
1944 & 9,039 & 448 \\
\hline
\end{tabular}

between 1942 and 1945 are not very reliable, due to conditions prevailing at that time.

Population figures during the Japapese régime were unascertainable; hence comparison has to be made between the actual number of deaths of these two periods, and not between the infantile death rates. 
Etiology

At that time the increasing incidence of beri-beri among the population showed that deficiency of vitamin $B_{1}$ constituted a serious menace to public health. Infantile beri-beri developed either: (a) in children fed on the breast milk of a woman whose diet consisted exclusively of highly milled rice or who was herself suffering from latent or manifest beri-beri (in most instances the mother appeared healthy); or (b) in children fed either on food poor in vitamins, such as highly milled rice paste, or on locally made condensed or evaporated milk introduced as substitutes for powdered milk; or (c) in children fed on cow's milk with a very low vitamin $B_{1}$ content.

Eijkman (1897), as the result of experiments on fowls, wrongly postulated that there exists in rice a toxin which produces polyneuritis and that this toxin could be neutralized by something present in the pericarp. Grijns (1901), thought that infection and intoxication played no part in the causation of this disease and that it was the result of food deficiency. Braddon (1901, 1907), Fletcher (1907), and Fraser and Stanton (1909, 1910), from investigations carried out in the Federated. Malay States on the etiology of beri-beri, proved that beri-beri appears in persons who almost exclusively eat highly milled rice, and that the consumption of under-milled rice or the administration of the silvery coverings of the rice was potent not only in stopping the development of beri-beri but also in curing it. Ito (1911), observed a case of infantile beri-beri in which the mother did not have beri-beri, and called the condition 'mother's-milk intoxication.' But he afterwards changed the name to 'breast-milk intoxication' because he saw cases in babies who were fed by wet nurses. In 1916, Segawa reported an interesting case in which nervous symptoms in a breast-fed infant disappeared when fixed feeding was given. The mother of the infant did not have beri-beri, so Segawa thought that in addition to infantile beriberi there was another disease of infants due to breast feeding. This was the first case reported of what is now termed 'so-called breast-milk intoxica- tion.' The nervous symptoms vanished quickly when the mother ceased to feed her baby, and reappeared when the milk of the mother was again used. Segawa concluded, therefore, that the cause of the sickness must lie in breast milk and that the malady is not the same as infantile beri-beri. Inaba (1917), insisted that, although cardiac disturbances are the most important symptoms of infantile beriberi, the nervous manifestations of so-called breastmilk intoxication may also be seen in infantile beriberi and are not incompatible with that diagnosis. Because of the rapidity of recovery from so-called breast-milk intoxication when patients are given vitamin $B_{1}$, Toyoda (1922) thought that the cause of the sickness was the same as that inducing infantile beri-beti.

\section{Age}

In this series of cases of infantile beri-beri, 123 were breast fed, and 14 were fed on locally made condensed or evaporated milk (see table 4). In the breast-fed group, the cases occurred with greatest frequency between the one month and four months age periods. It was also noted with less frequency in children between the seventh and eleventh months. The lowest age on record in this series was in a locallymade condensed-milk-fed infant aged seven days (case 1). The highest age on record is in a child of two years. It is included here because it happened to be breast-fed (case 2).

\section{INFANT FEEDING}

Certain problems of infant feeding presented themselves for solution during the Japanese occupation period. Firstly there was the increased incidence of beri-beri in pregnant woman, nursing mothers, and breast-fed children owing to the consumption of an exclusive diet of highly milled rice and/or tapioca or sweet potato with no vitamin $B_{1}$ supplement. Then we were faced with the problem of providing suitable substitutes for milk when the then existing stocks of condensed milk became exhausted. There were not enough milch cows to cater for the needs of all infants who for various reasons could not be breast-fed. Even when cow's

TABLE 4

\begin{tabular}{|c|c|c|c|c|c|c|c|c|c|c|c|c|c|c|c|}
\hline $\begin{array}{l}\text { Age in months } \\
\text { and days }\end{array}$ & $\begin{array}{c}7 \\
\text { days }\end{array}$ & mth. & $\begin{array}{c}2 \\
\text { mths. }\end{array}$ & $\begin{array}{c}3 \\
\text { mths. }\end{array}$ & $\begin{array}{c}4 \\
\text { mths. }\end{array}$ & $\begin{array}{c}5 \\
\text { mths. }\end{array}$ & $\begin{array}{c}6 \\
\text { mths. }\end{array}$ & $\begin{array}{c}7 \\
\text { mths. }\end{array}$ & $\begin{array}{c}8 \\
\text { mths. }\end{array}$ & $\begin{array}{c}9 \\
\text { mths. }\end{array}$ & $\begin{array}{c}10 \\
\text { mths. }\end{array}$ & $\begin{array}{c}11 \\
\text { mths. }\end{array}$ & mths. & 24 & Total \\
\hline Breast-fed & 0 & 27 & 32 & 16 & 11 & 7 & 7 & 2 & 2 & 6 & 2 & 0 & 10 & 1 & 123 \\
\hline $\begin{array}{l}\text { Condensed milk, } \\
\text { locally made }\end{array}$ & 1 & 1 & 1 & 2 & 3 & 1 & $\mathbf{0}$ & 2 & 1 & 0 & 1 & 0 & 1 & 0 & 14 \\
\hline Cow's milk & $\mathbf{0}$ & $\mathbf{0}$ & $\mathbf{0}$ & 1 & 1 & $\mathbf{0}$ & $\mathbf{0}$ & $\mathbf{0}$ & $\mathbf{0}$ & $\mathbf{0}$ & 0 & $\mathbf{0}$ & 0 & $\mathbf{0}$ & 2 \\
\hline
\end{tabular}


milk was available, its purchase was not within the financial means of the poorer section of the population. Mothers who had too little breast milk, or those who could not obtain milk as a substitute, used to give the most easily obtainable food, that is, cooked highly milled rice, which was given in spoonfuls and was stuffed into the children's mouths in the form of a thin gruel or a rice-paste without any vitamin $B_{1}$ supplements. Among the Malays bananas were often given, both alone and mixed with highly milled rice: and in Malay children primary dietetic disturbances and infantile beri-beri were rare, the diet of rice and bananas being quite well borne. But much of the trouble resulted from the very insanitary way in which the food was stored and prepared, and from the method of administering the feeds.

Soya bean milk and sifted undermilled rice flour (or Chowbee, or bras ayam) with certain additions to make good the deficiency in fats and in vitamins $A$ and $C$, were recommended as suitable substitutes for milk.

Method of preparation of soya bean milk. For one pint of milk take $2 \frac{1}{2}$ dessertspoonfuls of the raw beans, wash well, and soak in water overnight. Next morning pound or grind the beans (wet). Add the required amount of water and boil for 5 or 10 minutes, stirring all the time. Then strain through a thin cloth or strainer and add sugar to taste. It can be given in a bottle like milk. So that it will keep till late afternoon, it is advisable not to add sugar till the food is used, and also to keep the milk in a cool place.

Method of preparation of rice gruel as a substitute for milk. Rice gruel prepared from sifted undermilled rice flour (or Chowbee, or bras ayam), with some additions such as red palm oil and pineapple juice to make good the deficiency in vitamins $A$ and $C$, was recommended as another suitable substitute for milk when the latter was not obtainable. Rice gruel made from sifted undermilled rice flour (or chowbee or bras ayam) was analysed by Rosedale (unpublished data) and was found to work out roughly at half the value of fresh milk, with the following differences: (a) gruel from sifted undermilled rice flour is rich in vitamin $B_{1}$; (b) it is notably deficient in fat and the fat is never higher than half per cent. (good milk contains at least three per cent. of fat); (c) vitamins $A$ and $C$ are completely absent in these gruels; (d) calcium is markedly deficient; (e) carbohydrate present is starch and not lactose. (The disadvantage of starch is that in infants under six months of age the digestion of starch is poor; but a choice between starvation, or an unsuitable starchy substitute such as undermilled rice gruel, must favour the latter.)

Method of preparation of gruel, and dosage. Take two full or heaped teaspoonfuls of the sifted rice flour, add to three ounces of water, and cook for a quarter of an hour. This forms a suitable feed for babies below four months old. From five months onwards the quantity of ground rice-flour is to be increased gradually from two to three heaped teaspoonfuls for five ounces of water. The quantity of water has to be greatly increased. From six months onwards little extras (e.g. ripe bananas, fish liver, egg, spinach, bean curd) should be added to the diet from time to time. For additional fat, it is suggested that one drachm or one teaspoonful of a mixture of one part of refined red palm oil and five parts of coconut oil be added to each of the child's feeds in the day for an infant up to one year, assuming that the infant has six or seven feeds in the day. This will greatly enhance the vitamin $A$ value. The deficiency in vitamin $C$ can be made up by giving the infant the juice of ripe pineapples, commencing with one teaspoonful once a day, gradually increasing this amount to one teaspoonful three times a day.

\section{Race Distribution}

Table 5 gives the race distribution of cases of beriberi. The occurrence of infantile beri-beri following the consumption of milk per se, or of condensed

TABLE 5

\begin{tabular}{c|c|c|c|c}
\hline Race & Chinese & Eurasians & Indians & Total \\
\hline $\begin{array}{c}\text { Breast-fed . } \\
\text { Locally made } \\
\text { condensed } \\
\text { milk }\end{array}$ & 120 & 1 & 2 & 123 \\
\begin{tabular}{c} 
Cow's milk \\
\hline
\end{tabular} & 14 & - & -1 & 14 \\
\hline
\end{tabular}

or evaporated milk produced locally, may be due to the fact that suitable fodder for cows was scarce, with the result that the vitamin $B_{1}$ content of the milk must have been low; this amount would have been still further reduced by the unsatisfactory methods employed in the manufacture of the condensed or evaporated milk.

The sale of cow's milk was not controlled by the authorities, and the following brands of cow's milk were available: (1) undiluted cow's milk at $\$ 15.00$ per pau, Japanese currency (pre-war price ten cents per pau (1 pau=10 oz.) ); (2) moderately diluted cow's milk at $\$ 10.00$ per pau; (3) highly diluted cow's milk at $\$ 5.00$ per pau. Brand 3 , being the cheapest, was bought by the people for feeding their infants, and it is not surprising that infantile beriberi occurred in infants thus fed.

There were two South Indian (Tamil) cases in this series. The comparative rarity of infantile beriberi among the South Indian (Tamil) in spite of the diet of highly milled rice and/or tapioca is probably due to the consumption of other foods rich in vitamin $B_{1}$, such as ragi (Eleusine Corocona) which was cultivated to a far greater extent in Malaya than hitherto. The South Indians find ragi much more acceptable 
as a food than do the Chinese. Under normal prewar conditions, it was noted that very few cases of infantile beri-beri were encountered among the South Indians, as their staple diet consisted mainly of parboiled rice which contained a fair amount of vitamin $\mathbf{B}_{1}$.

\section{Economic Status}

During the period under review the economic situation of the country was chaotic. Owing to the stranglehold exerted by the Allies on Japanese communications, there was an evergrowing shortage of essential foodstuffs. Inflation was marked and the purchasing value of the currency very low. Black market activities were rampant. The prices of essential foodstuffs, such as milk, eggs, meats, fish, peas, and beans, increased to an extent far beyond the reach of the average individual. Parboiled rice was not obtainable, and there were only limited stocks of undermilled rice or bras ayam or chowbee, which were sold at a high price. The rice rations per month were cut down in January, 1944, to 10,8 , and $5 \mathrm{lb}$. respectively for men, women, and children under ten years of age. In order to supplement the inadequate rice ration, sweet potatoes and/or tapioca-foodstuffs of poor nutritive value-were eaten by most people. In some instances the fathers of the infants were unemployed, in others a father with small earnings had to keep a family of five or six. Occasionally the parents were miserly in spending money on protective foods.

\section{Dietetic History}

The following is a typical economic and diet history obtained from a mother of a child with infantile beri-beri.

The mother lives with a big family, which consists of eleven persons including herself. The family owns and cultivates a piece of land, grows vegetables, rears pigs, fowls, ducks, etc. Their income is just enough to keep the farm going and to feed and clothe the family. There is little money saved. The mother's meals are: 8 a.m., kunji (rice gruel), vegetables; 1 p.m., highly milled rice, vegetables, and fish occasionally; 6 p.m., highly milled rice, vegetables, and meat (very rarely). The mother differs from the rest of the family in that she has a very poor appetite, eats little, and sometimes misses meals altogether. In some cases tapioca and/or sweet potato has to be substituted for highly milled rice. In others, kunji (rice gruel) and salt fish for one month after the birth of the child; after this rice, salted eggs, and pork (a little) comprises the diet. It is obvious that the above diets are deficient in vitamin $B_{1}$ and several other food nutrients. The circumstances leading these mothers to take these diets are either (a) poverty or (b) a belief among Chinese mothers who are breast feeding that if they partake of foods such as green vegetables, green peas, towgay, and fruits, especially during the first month of the lactation period, their infants will suffer from diarrhoea or may get wind or ' hong.'

Out of eighteen mothers examined for symptoms of beri-beri, eleven were found to be suffering from some form or other of the disease, such as palpitations, creeping sensations, numbness and tingling in the lower extremities, weakness of legs, slight oedema of ankles, tenderness of the calves with absence of knee- and ankle-jerks.

\section{Types of Beri-beri}

Joêé Albert of Manila in 1932 drew attention to three types of infantile beri-beri: (1) the aphonic; (2) the pseudo-meningeal; and (3) the cardiac. In my series of cases the types recognized are: (1) the aphonic; (2) the peripheral neuritic; (3) the cardiac; and (4) the pseudo-meningeal. These four types may exist separately, or there may be a combination of one or more types in an individual case. The commonest form was a combination of the cardiac

TABLE 6

\begin{tabular}{l|l|c|c|c|c|c|c|c|c|c|c|c|c|c}
\hline & Types & C. & $\begin{array}{c}\text { C.: } \\
\text { P.N. }\end{array}$ & C:A. & P.N. & A. & $\begin{array}{c}\text { P.N.: } \\
\text { A.: }\end{array}$ & P.M. & $\begin{array}{c}\text { P.M: } \\
\text { A. }\end{array}$ & $\begin{array}{c}\text { P.M: } \\
\text { C. }\end{array}$ & $\begin{array}{c}\text { P.M: } \\
\text { A: } \\
\text { P.N. }\end{array}$ & $\begin{array}{c}\text { P.M: } \\
\text { P.N. }\end{array}$ & $\begin{array}{c}\text { P.M: } \\
\text { C.: }\end{array}$ & Total \\
\hline $\begin{array}{l}\text { Breast- } \\
\text { fed }\end{array}$ & Cases & 31 & 53 & 4 & 5 & 3 & 10 & 5 & 2 & 1 & 1 & 3 & 5 & 123 \\
\hline $\begin{array}{l}\text { Local } \\
\text { condensed } \\
\text { milk }\end{array}$ & Deaths & 16 & 32 & 1 & 4 & 1 & 7 & 1 & 1 & - & 1 & 2 & 4 & 70 \\
\hline $\begin{array}{l}\text { Cowss } \\
\text { milk }\end{array}$ & Deaths & - & 5 & - & - & 1 & - & - & - & - & - & - & - & 6 \\
\hline
\end{tabular}

Key to abbreviations : C.=Cardiac. P.N.=Peripheral Neuritic. $A=$ Aphonic. P.M. $=$ Pseudo-Men ingeal. 
and peripheral neuritic type, of which 62 cases occurred in this series (see table 6). Next in order of frequency was the pure cardiac type, with 33 cases. The pseudo-meningeal type in various combinations occurred in 19 cases. The cardiac type and its combinations gave rise to the severest symptoms and claimed the greatest number of deaths. The two deaths in the pure aphonic type were due to enteritis and bronchopneumonia respectively. In the peripheral neuritic type, deaths were due to either enteritis of bronchopneumonia.

\section{Mortality Rate}

One hundred and thirty-nine cases of infantile beriberi, with 77 deaths, gives a percentage mortality of 55.41 per cent. This high mortality rate is due to the fact that, owing to the low stocks of vitamin $B_{1}$ existing, doses extremely inadequate to cope with the immediate acute fulminating attacks were released for use in each case by the Japanese authorities in charge. There was also a considerable time-lag factor between seeing the patient and the administration of the vitamin as, certain ' red tape' formalities had to be undergone before sanction to obtain this vitamin was permitted.

\section{Symptomatology}

The symptoms for which the infants were brought to hospital were many and varied. They included varying degrees of dyspnoea; refusing feeds, vomiting feeds, and diarrhoea; vomiting and cough, vomiting and crying continuously; constipation; no voice, husky or weak voice; inability to pass urine; inability to cry; fits; crying excessively; scanty urine; cedema of feet and legs; restlessness; flatulence; drowsiness; and convulsions. It was only after obtaining a careful history and examining the case systematically that true nature of the condition became evident.

Fever and cough were indications of the onset of respiratory-tract infection in the form of acute nasopharyngitis, bronchitis, or bronchopneumonia. These acted as exciting causes for the more urgent cardiac symptoms of infantile beri-beri. Fever and cough have been recorded for periods varying from three days up to a month before the onset of symptoms of infantile beri-beri. Other associated respiratory conditions were pulmonary oedema and congestion of the lungs.

Of the gastrointestinal symptoms, refusal of feeds, vomiting, and diarrhoea were the commonest; occasionally there was constipation or abdominal distension due to acute and persistent gaseous distension of the stomach and intestines. Refusal of feeds indicated anorexia, which, with vomiting, was the earliest symptom to appear. Vomiting varied from a small amount to the return of the whole feed, and was sometimes followed by diarrhoea. These dyspeptic symptoms might last from a few days to a month before the onset of cardiac symptoms. It is possible that this dyspepsia was, like malaria in adult cardiac beri-beri, only a common exciting cause.

Aphonia varied from slight hoarseness to complete loss of voice. It was noticed in 20 out of 139 cases. Pure aphonia was an indication of a mild attack of beri-beri, and it was found in association with the cardiac, the peripheral neuritic, and the pseudo-meningeal types. It was often persistent, and continued after all other symptoms had cleared. Direct laryngoscopy performed on a series of cases revealed that there was oedema round about the arytenoids, and it seems possible that the aphonia was due to this oedema. Wenckebach (1935) ascribes the aphonia to a paralysis of the recurrent laryngeal nerve, which at first is oedematous but later becomes permanently degenerated due to pressure from below by the dilated right heart as it slips round under the arch of the aorta.

The restlessness, fretfulness, and incessant crying in some cases may have been due to abdominal distension or to cough and dyspnoea.

The cardiovascular symptoms of infantile beriberi are multiple. The first sign of circulatory insufficiency was persistently rapid heart rate which fluctuated with the pulse rate. Early in the disease there was slight cyanosis, mostly noticeable around the lips, and the breathing became somewhat difficult. Shortly after, dyspnoea was sometimes observed. The second pulmonic sound would become markedly accentuated and might be heard over the sternum, denoting dilatation of the right heart and increased pressure of the pulmonary circulation. The dilatation might extend considerably beyond the right sternal border, and could be demonstrated by percussion. In grave cases the heart sounds had a galloping rhythm. With further changes in the cardiac muscle the dyspnoea became more marked, the accessory muscles of respiration came into action, the alae nasi worked rapidly, and respiratory retraction of the thorax was observed. If the child cried during this stage, cyanosis was more marked and the child grunted with each respiration. During an acute attack there was extreme pallor and the voice became feeble and whispering. Frequently the infant contracted his face and mourned pitifully, as though suffering great pain, became apathetic and very soon comatose. The extremities became cold and the infant was bathed in perspiration. Sometimes there were twitchings of the extremities and the head was retracted; occasionally there might be high fever. The skin became congested and mottled, and the liver much enlarged. Dyspnoea became more and more severe, and death ensued.

Oedema was generally slight or moderate, and appeared chiefly on the face and extremities. It often occurred in association with diminution of urine. 
Listlessness and limpness of the limbs were noticed and the child 'would not play.' Pseudomeningeal symptoms varying from mild twitchings of limbs to violent convulsive movements. Sometimes there was rigidity of the neck with tenseness of the anterior fontanelle. The infant grew either drowsy or unconscious. Lumbar puncture revealed a cerebrospinal fluid that came out under increased pressure and was clear, with practically no increase in cells or albumin. Knee-jerks and ankle-jerks were absent if there was a peripheral neuritis. In the present series there were nineteen cases with ten deaths, giving a mortality of 52.16 per cent. Urinary symptoms varied from diminution in the amount of urine passed to almost complete suppression.

\section{Physical Examination}

The patients in this series can be divided into two groups.

The first group of children appeared to be well nourished but were a little pale and flabby. There was sometimes slight duskiness about the lips which could be detected only by careful observation. The child was usually brought to the out-patient department because of listlessness, limpness of the limbs, huskiness, breathlessness, or because it would not play. The heart rate was usually rapid, the liver enlarged; and the knee- and ankle-jerks might or might not be absent. This group of children apparently thriving on breast milk, were suffering from the effects of vitamin $B_{1}$ deficiency (see fig. 1, p. 17).

The second group of children, in addition to suffering from the effects of a lack of vitamin $B_{1}$ in breast milk, were also not thriving on it. They showed marked pallor and were undernourished. Slight puffiness of the face and slight oedema of the hands and feet were present. They were restless, breathed rapidly with little or no sound, the feeds were returned, and there might be severe vomiting. There was sometimes a weak cough with no physical signs in the lungs. The heart beat was fast, weak, and regular, usually with no murmurs. The kneeand ankle-jerks were absent.

A careful inquiry into the health of the mother during pregnancy, and particularly into her diet during the last month of pregnancy and during lactation, should be made in every case to determine whether she received an adequate diet. It is necessary to bear in mind that an infant can have his knee- and ankle-jerks present and yet suffer from beri-beri. This has been proved by postmortem examinations on cases whose knee- and ankle-jerks were present and who died of an acute cardiac attack. The type of case that presents difficulty in diagnosis is the case with only one symptom, like hoarseness of voice. If the knee- and ankle-jerks are present, then the presence of tachycardia, dilated heart, and enlarged liver with evidences of circulatory failure, coupled with a history of breast-feeding on a vitamin $B_{1}$ deficient diet, will make the diagnosis easy. If there is no history of breast-feeding and the infant is fed on locally made condensed milk or on a dilution of cow's milk and is suffering from aphonia, diagnosis is a little more difficult. It has to be made by a process of exclusion and by a therapeutic test, that is, improvement with parenteral administration of vitamin $\mathbf{B}_{\mathbf{1}}$.

\section{Mlustrative Case Reports}

CASE 1. The youngest case in the series. A Chinese Teochew male infant, aged seven days, was brought to hospital on May 25, 1944 . No history was obtainable as the mother was ill at home. The infant was fed on condensed milk. On admission the infant was poorly nourished and dyspnoeic. He had a temperature of $99.5^{\circ} \mathrm{F}$. and the pulse and heart rates were rapid. The cord had dropped off the umbilicus and there was no sepsis. The knee-jerks were absent. Only $1 \mathrm{mg}$. of vitamin $B_{1}$ was available for parenteral administration. The infant died the next day. This was a case of infantile beri-beri of the cardiac and peripheral neuritic type.

CASE 2. The oldest case in the series. A Chinese Cantonese female child, aged two years, was brought to hospital on June 19, 1944, with a history of diarrhoea, vomiting, fever, and slight cough for four days. The child was breast-fed. On examination, the child was febrile, the extremities were cold, and she was dehydrated and moribund. There was some cyanosis and congestive mottling of the skin. The heart was rapid and there were few crepitations in the lungs. The liver was little larger than normal, and knee- and ankle-jerks were not elicited. A diagnosis of gastro-enteritis and infantile beri-beri of the cardiac and peripheral neuritic types was established. The child died six hours after admission. No vitamin $B_{1}$ was available for treatment.

The following case report is that of a case not included in the series.

A Chinese Hokkien female breast-fed infant, aged five months, was admitted to hospital with a history of loss of appetite. The mother was suffering from herpes zoster over the right side of the chest, and she had ceased breast-feeding four days before admission. The infant was found to be pale, undernourished, cyanosed, and dyspnoeic, with a feeble cry. There was a rise of temperature, and the heart rate was rapid. The lungs were full of moist sounds. The liver was larger than normal. The knee- and ankle-jerks were absent. A diagnosis of infantile beri-beri of the cardiac, aphonic, and peripheral neuritic types with associated lung infection was made. The general condition of the infant at that 


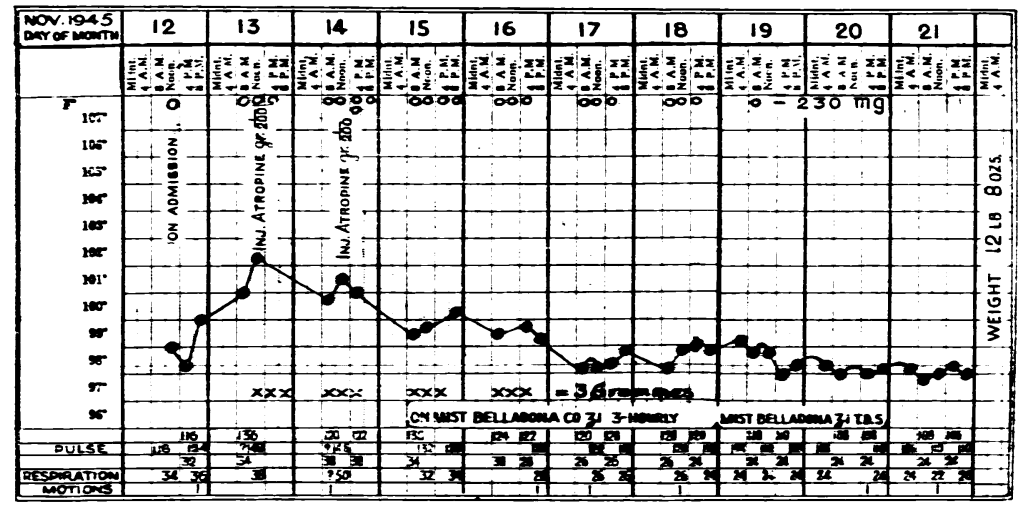

Fig. 2. Temperature chart of a child aged five months, receiving sulphonamide-P and injections of vitamin $B_{1}$. $X=$ sulphonamide, $0-25 \mathrm{~g}$. $O=$ injections of vitamin $B_{1}, 10 \mathrm{mg}$. intramuscularly.

time was so grave the vigorous anti-beri-beri treatment and treatment to control the lung infection was instituted immediately. Altogether, within a period of six days, $230 \mathrm{mg}$. of vitamin $B_{1}$ intramuscularly, and $3 \mathrm{~g}$. of sulphonamide-P by mouth were administered (see temperature chart, fig 2). At the end of this period, there was no cyanosis and no dyspnoea. The colour of the infant had improved. Its lips and tongue were pink. The heart sounds were not so rapid, and there were only coarse rhonchi in the lungs. The liver had diminished in size. The knee- and ankle-jerks had returned. The infant was quite hungry and finished all its feeds. The feeble voice took about six weeks to improve. For treatment, the infant had $230 \mathrm{mg}$. of vitamin $B_{1}$ intramuscularly, two injections of atropine sulphate gr. $\frac{1}{200}$ each, sulphonamide $3 \mathrm{~g}$., and belladonna mixture.

\section{Differential Diagnosis}

The following diseases have to be distinguished from infantile beri-beri: (1) idiopathic cardiac hypertrophy; (2) improper feeding and indigestion; (3) congenital heart disease; (4) respiratory diseases; (5) infantile muscular atrophy of spinal origin; (6) diffuse poliomyelitis; (7) diphtheritic paralysis; (8) nephritis; (9) meningitis; (10) laryngeal diphtheria; (11) laryngitis of measles.

1. A patient suffering form idiopathic cardiac hypertrophy, has to be distinguished from an infant with the cardiac condition in beri-beri. There is a striking clinical similarity in the two conditions, but a history of vitamin $B_{1}$ deficiency in the beri-beri infant's mother's diet will help to differentiate these conditions. On post-mortem examination the right ventricle of the heart is most seriously involved in beri-beri, while in idiopathic hypertrophy both sides of the heart are attacked, the hypertrophy and dilatation of left ventricle predominating. If there is no history of breast-feeding, then the possibility of a clinical syndrome fitting in with the description of infantile beri-beri in a locally-made condensed-milkfed baby should be considered. A therapeutic test should be applied to settle the diagnosis. A case of infantile beri-beri will improve with vitamin $\mathbf{B}_{1}$ injections.

2. Failure of the infant to gain weight on the breast, with some colic, restlessness, and constant crying, may occur in an underfed infant; and the grosser symptoms of indigestion, such as vomiting, colic, and diarrhoea may be due to overfeeding or to infection in a breast-fed infant and yet the infant may not be suffering from infantile beri-beri. These symptoms may exist in association with infantile beri-beri or act as a common exciting cause of the syndrome.

3. The diagnosis of cyanosis and dyspnoea of congenital heart disease will be confirmed by (a) the presence of a murmur and its location (b) the presence of clubbing of the fingers and toes in some cases (c) a history of cyanosis from birth. A dilatation of the right side of the heart and an enlarged liver are present in congenital heart disease and in infantile beri-beri. In the latter condition a history of breast-feeding on a vitamin $B_{1}$ deficient diet will be obtained.

4. In cyanosis and dyspnoea of respiratory origin which may be due to laryngeal, tracheal, or bronchial obstruction, bronchitis, bronchopneumonia, or atelectasis, the history and the presence of physical signs in the chest will make the diagnosis clear. Differentiation may be difficult in a case where bronchopneumonia occurs as a terminal event in beri-beri. Here again the history will be helpful in suspecting the condition.

5. Infantile muscular atrophy of spinal origin which occurs in an infant in the first weeks or months of life and where the infant develops a flaccid paralysis of all the extremities will not present much difficulty in diagnosis. 
6 and 7. Diffuse poliomyelitis and diphtheritic paralysis have to be differentiated from infantile beri-beri with neuritic symptoms In diffuse poliomyelitis, the paralysis and atrophy of muscles is rarely symmetrical and groups of muscles tend to be affected. In a case of diphtheritic paralysis, in addition to the incomplete paralysis of the limbs, the eyes and palatal and laryngeal muscles are affected and the diaphragm is weak. In infantile beri-beri, as opposed to these two conditions, there is no definite paralysis and the neuritis of the lower limbs is symmetrical.

8. A case of oedema from nephritis can be distinguished from infantile beri-beri with oedema by the presence of albumin in the urine.

9. Children admitted into hospital for convulsions due to beri-beri may have to be distinguished from those with convulsions due to meningitis by the absence of other symptoms of meningitis, such as bulging and tenseness of the anterior fontanelle, arching of the back and neck, internal squint, and exaggerated reflexes. In meningitis, lumbar puncture will reveal an abnormal cerebrospinal fluid. The convulsions in beri-beri have improved after treatment with vitamin $B_{1}$ and have not been known to recur.

10 and 11. The aphonic type will have to be differentiated from laryngeal diphtheria and laryngitis occurring at the onset of an attack of measles. In laryngeal diphtheria, careful examination of the throat will reveal a patch of membrane in an exposed situation, and from the throat swab the diphtheria bacillus will be cultured. The laryngitis occurring at the onset of an attack of measles may give rise to doubt as to diagnosis. But the presence of pyrexia and the discovery of Koplik's spots on the buccal mucosa will solve the problem.

The importance of giving an injection of $10 \mathrm{mg}$. of vitamin $B_{1}$ when in doubt about the diagnosis must be emphasized. An improvement in the symptoms will be noticed if it is a case of infantile beri-beri.

\section{Post-mortem Findings}

The following is a verbatim description given by Tull, quoted by Wenckebach (1935): 'The interior of the thorax was a really wonderful sight, the right heart extending greatly to the right, the surface shining, the vessels under the pericardium much engorged and the right ventricle dilated to almost breaking point. The pulmonary artery was the same size as the aorta. The heart was as large as that of a normal child ten years old.' In the same case 'the liver was much enlarged and the wall of the gall-bladder typically oedematous; there was complete absence of cedema of lungs.' In the present series of cases there were a number with oedema of the lungs, some with congestion of the lungs and bronchopneumonia. In the nervous system there was marked engorgement of the cerebral blood vessels. There was a small amount of effusion in the pericardial sac and in the abdominal cavity.

\section{Prognosis}

In the aphonic type it takes about six weeks for the voice to recover.

In the pseudo-meningeal type, without complications, the prognosis is good provided adequate doses of vitamin $B_{1}$ are administered parenterally. If there is a rise of temperature, malarial infection must be excluded by an examination of the bloodfilm. During an attack of convulsions, the throat must be cleared to prevent death from suffocation.

In the cardiac type, cold, clammy hands and feet are signs of grave circulatory failure. Therefore, in such cases, treatment for restoration of circulation should be energetic because it is abșolutely essential to keep the heart going until such time as vitamin $B_{1}$ injections take effect. Very often cases are brought into hospital where the circulatory failure is so severe that the infant dies before anything can be done for its restoration.

The old idea that a beri-beri heart is permanently damaged does not hold good, provided adequate doses of vitamin $B_{1}$ are administered during the acute stage. A follow-up of cases of acute beri-beri that have recovered shows that, given the same chances as a normal infant in regard to diet and care, the former invariably grow up to be healthy and strong.

In certain cases, an acute cardiac attack supervenes upon a subacute cardiac condition which had been undiagnosed for a long period. In such cases there is considerable oedema of the heart muscles, and thus they fail to recover even after an injection of 60 to $80 \mathrm{mg}$. of vitamin $B_{1}$.

Expiratory grunt is an unmistakable sign of an acute cardiac attack. This sign can be recognized from a great distance. Anxious parents often ask, 'When will the infant be out of danger?' It is possible to say that the vitamin $B_{1}$ injection will take at least one and a half to two hours to have effect, and that, if the infant's heart will respond to the drug, it should recover. It takes about one and a half to one and three-quarter hours for the grunt to cease in favourable cases. In cases that are going to end unfavourably, the grunt ceases rather early, that is, within a period of about three-quarters to one hour after the vitamin $B_{1}$ administration. The infant's respiratory system often gets choked with secretion, the heart sounds become feeble, and it dies.

Numerous fine crepitations at both bases, and bronchial breath sounds are associated with grave prognosis. Some cases which get cured rapidly in 
twenty-four hours, and are sent home, are brought back at the end of the second day with signs of acute bronchitis developing rapidly into acute bronchopneumonia. The cause of this is probably either (a) associated avitaminosis $A$ and $D$ predisposing to respiratory tract infection, or (b) inhalation of infected mucus during the acute stage. In such cases it is advisable to administer sulphonamide-P as a measure of prophylaxis if the temperature rises on the second day.

\section{Treatment}

The treatment of infantile beri-beri can be divided into: (1) treatment of the mother; (2) treatment of the infant.

Treatment of the mother consists in attention to her health and diet during pregnancy and during the lactation period. As parboiled or undermilled rice was not obtainable, overmilled rice and/or tapioca or sweet potato had to be taken. Tapioca, sweet potato, and overmilled rice contain small amounts of vitamin $B_{1}$. In the process of milling the rice, the vitamin $B_{1}$ which is found in the husk and outer layers of the grain is removed. The very valuable mineral salts are also removed with the husk. As, through ignorance, the public do not supplement the diet with vitamin $B_{1}$, hypovitaminosis $B_{1}$ results. The consumption of an exclusive diet of overmilled rice is harmful, because the high carbohydrate diet will require a correspondingly high ingestion of vitamin-B $B_{1}$-containing foods. Good sources of vitamin $B_{1}$ are soya bean, green dhall, peanut, rice polishings, husked rice, hen egg, duck egg, and salted duck egg.

The data in table 7 have been obtained from Leong (1940), who did a fairly complete assay of the $B_{1}$ content of foods obtainable in Malaya. Because of the peculiar belief that green dhall, green vegetable, and bean sprouts will give rise to wind or ' hong' in the mother and green diarrhoea in the infant, it is difficult to make the mothers take these foods. The mothers were warned of the dangers of abstention from these valuable foods. If the mothers refused to take them in spite of advice, weekly or fortnightly intramuscular injections of vitamin $B_{1}$ or tablets of this vitamin were given. The mother should be examined for signs and symptoms of vitamin $B_{1}$ deficiency, such as creeping sensations, numbness and tingling in the lower extremities, weakness of legs and slight oedema of the ankles, tenderness of calves with absence of knee- and ankle-jerks.

The most dangerous feature of infantile beri-beri is that the mother does not realize the gravity of the disease in her infant until alarming symptoms develop. We always advocate that all infants from poor families should be brought to the outpatient department for attention and advice. The medical officer could detect the symptoms of beriberi in its early stages and give suitable advice and treatment.

Before the introduction of vitamin $B_{1}$ for parenteral administration, treament of the baby consisted of (1) weaning the infant from the breast and administering condensed milk feeds; (2) giving brewer's yeast powder or Marmite; (3) administering cardiac stimulants in cardiac failure, and oxygen for the cyanosis. This line of treatment proved unsatisfactory. Since the introduction of potent vitamin $B_{1}$ preparations, we have been able to introduce systematic treatment. If the case belongs to the group which has been described previously as

TABLE 7

VITAMIN $B_{1}$ CONTENT OF FOODS

\begin{tabular}{|c|c|c|c|}
\hline English name & Scientific name & Local name & $\begin{array}{c}\text { International } \\
\text { Units per } 100 \mathrm{~g} .\end{array}$ \\
\hline 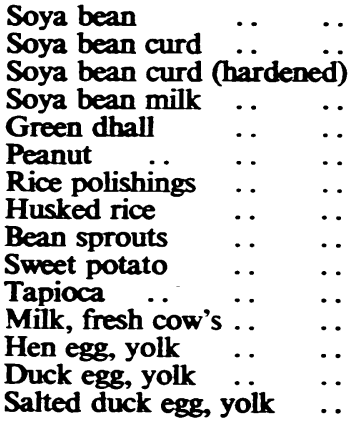 & $\begin{array}{c}\text { Glycine hispida } \\
\text {," ", } \\
\text { ", ", } \\
\text { Phaseolus radiatus } \\
\text { Arachis hypogea } \\
\text { - } \\
\text { Oryza sativa } \\
\text { Phaseolus radiatus } \\
\text { Ipomoea batatas } \\
\text { Manihotutillissima } \\
\text { _- } \\
\text { _- }\end{array}$ & $\begin{array}{l}\text { Kachang Soya } \\
\text { Tauhu } \\
\text { Towkua } \\
\text { Kachang hijau } \\
\text { Kachang goreng } \\
\text { Dedak } \\
\text { Bras ayam } \\
\text { Taugeh } \\
\text { Keledek } \\
\text { Ubi kayu } \\
\text { Susu lembu } \\
\text { Telor ayam } \\
\text { Telor itek } \\
\text { Telok asin }\end{array}$ & $\begin{array}{l}240 \\
11 \\
43 \\
8 \\
270 \\
235 \text { (baked) } \\
600-800 \\
140 \\
13 \text { (fried) } \\
28 \text { (boiled) } \\
19 \text { (boiled) } \\
3 \text {. } \\
110-270 \text { (boiled) } \\
200-375 \text { (boiled) } \\
210-440 \text { (boiled) }\end{array}$ \\
\hline
\end{tabular}


thriving on breast milk but which is only manifesting symptoms of vitamin $B_{1}$ deficiency, the treatment is as follows: (1) breast-feeding is continued; (2) the mother is put on an anti-beri-beri diet consisting of husked rice or 'bras ayam' four ounces, soya bean curd or 'tauhu' four ounces; green vegetables four ounces; bean sprouts or 'taugeh' four ounces; green dhall two ounces; (3) she is given $10 \mathrm{mg}$. vitamin $B_{1}$ daily for six days, and this treatment is discontinued when once the symptoms in the child have improved; (4) the infant is given intramuscular or intravenous injections of vitamin $B_{1}$, the amount depending upon the severity of the case; (5) after discharge, the mother is instructed to follow a dietetic regimen similar to the one she had been taking in the ward, and to attend the outpatient department weekly.

Vitamin $B_{1}$ preparations have been put out for use in two forms, tablets for oral administration and solutions for parenteral administration, expressed in milligrammes ( $1 \mathrm{mg} .=333$ international units). For rapid effect, vitamin $B_{1}$ should be administered in large doses either intravenously or intracardiacally. It is excreted rapidly, and no toxic effects had been noted in my series of cases.

For intravenous administration, the superior longitudinal sinus through the anterior fontanelle is chosen. About $7 \mathrm{c.cm}$. of blood is withdrawn as a measure of venesection, and through the same needle $10 \mathrm{mg}$. of vitamin $B_{1}$ is injected. If there is no improvement within an hour, the injection is repeated. In addition, intramuscular injections of vitamin $B_{1}$ should be administered in $10 \mathrm{mg}$. doses. It is never safe to give less than $10 \mathrm{mg}$. as an initial dose. If, as occasionally happens, intravenous administration is unsuccessful, intracardiac injections must be given as a final resort. The disadvantage of this method is that the needle may not reach the heart, and if it does reach the heart there is considerable bruising of the myocardium, as has been demonstrated at autopsy on a few cases that have died.

The total dosage depends upon the severity of the case. In the milder cases about 20 to $25 \mathrm{mg}$., and in the more severe cases 60 to $70 \mathrm{mg}$. may be necessary before improvement in the condition is noted. The results of vitamin $B_{1}$ injection in cases that are improving are: (1) cyanosis lessens and disappears eventually; (2) dyspnoea improves; (3) the infant's colour improves; from the dusky colour of cyanosis, he becomes pink; (4) if he has been restless before, he now lies quietly in bed; $(5)$ the rate of the heart slows down; (6) vomiting disappears; (7) the knee- and ankle-jerks return in some cases where they have been absent before.

Symptomatic treatment consists of: (1) for persistent abdominal distension, flatus tube, rectal wash-out, and pituitrin 1 c.cm.; (2) injection of atropine sulphate, gr. $\frac{1}{300}$, for moist sounds in the lungs; (3) bromide and chloral for convulsions;
(4) $\mathrm{O}_{2}$ for the cyanosis; (5) treatment for rapid restoration of circulation as follows: (a) brandy to be rubbed on the lips; (b) brandy $\mathrm{Il} v$ in a teaspoonful of water to be given by mouth four-hourly; (c) one tablet of vitamin $B_{1}$ (1-2 mg.) with one drachm of carminative mixture for infants to be given half-hourly till improvement is noticed; (6) hot water bottles to be applied to limbs and sides of trunk; (7) do not push fluids too rapidly because the stomach will become distended and the infant will vomit with regurgitation of fluid into the lungs.

In dealing with the type that is not thriving on breast milk or where the mother is suffering from beri-beri, the infant is weaned and is given a suitable substitute feed to make good the vitamin deficiencies. The rest of the treatment is the same as that outlined for the type that is apparently thriving on breast milk.

If a breast-fed infant is brought to hospital for treatment of a complaint other then beri-beri, it is always advisable to administer a prophylatic dose of vitamin $B_{1}$ intramuscularly, say $5 \mathrm{mg}$., because a number of such children have collapsed suddenly and have died. Autopsy revealed the cause of death to be infantile beri-beri.

\section{Summary}

1. Infantile beri-beri is $B_{1}$ avitaminosis.

2. In Singapore during the latter part of the Japanese occupation it occurred in breast-fed, locally made condensed-milk-fed and very-occasionally in cow's-milk-fed infants.

3. It occurred in four forms: (a) aphonic; (b) peripheral neuritic; (c) acute cardiac; (d) pseudomeningeal.

4. The clinical signs indicating a cardiac attack are dyspnoea, cyanosis, tachycardia, dilatation of the right side of the heart, accentuation of the pulmonary second sound, and enlarged liver, and in extreme cases a congestive mottling of the skin.

5. It is not common in infants who are breast-fed by mothers who are poor and who eat unmilled rice.

6. It is common in the poor who eat highly milled rice.

7. An absence of knee- and ankle-jerks is not essential for the diagnosis. It may be purely a cardiac affection.

8. Vitamin $\mathbf{B}_{\mathbf{1}}$ solutions administered parenterally have proved satisfactory in the treatment of this condition.

9. It is never safe to give less than $10 \mathrm{mg}$. as an initial dose.

10. The diet of the nursing mother determines the condition of her milk.

11. The symptoms of vitamin $B_{1}$ deficiency in the mother are palpitations, creeping sensations, numbness and tingling in the lower extremities, weakness 
of legs, slight oedema of ankles, and tenderness of calves with absence of knee- and ankle-jerks.

Summary of Difficulties and New Features seen in Infantile Beri-beri during the Japanese Occupation Period.

1. Difficulty in getting vitamin $B_{1}$ in adequate amounts to save a case.

2. The prohibitive price, $10 \mathrm{mg}$. of locally prepared vitamin $B_{1}$ costing $\$ 250.00$ Japanese currency, and $10 \mathrm{mg}$. of foreign-prepared vitamin $B_{1}$ costing between $\$ 600.00$ to $\$ 700.00$ Japanese currency.

3. Secondary infections: frequency of lung complications, especially bronchopneumonia, after apparently efficient treatment. This was not seen in pre-war days.

4. Associated avitaminosis A, B, and D: more common in locally made condensed-milk-fed babies and probably also accounting for the secondary infection. Such children are pale and thin with subrickety manifestations.

5. Cardiac collapse is more severe.

I have to thank Colonel W. J. Wickers, Deputy Director of Civil Affairs (Medical), British Military Administration, Singapore, for permission to publish this paper, and Dr. C. J. Oliveiro, biochemist during the Japanese occupation period, for many useful suggestions in its compilation.

\section{REFERENCES}

Abt, Isaac A. (1935). Amer. J. Dis. Child., 50, 456.

Albert, J. (1932). Mschr. Kinderheilk., 54, 80.

Braddon, W. L. (1901). Fed. Malay St. Med. Arch. (1907). The Cause and Prevention of Beri-beri, London.

Eijkman, C. (1897). Virchows. Arch., 148, 523; 149, 187.

Fletcher, W. (1907). Lancet, 1, 1,776.

Fraser, H. and Stanton, A. T. (1909). Lancet, 1, 451.

- , (1909-1911). Studies from Inst. for Med. Res. Fed. Malay Str., Nos. 11 and 12, Singapore.

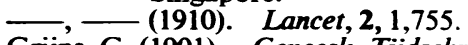

Grijns, G. (1901). Geneesk. Tijdschr. Ned.-Ind., 41, 3.

Haridas, G. (1937). J. Malaya Branch Brit. med. Ass., $1,26$.

Inaba, I. (1917). Zika-Zasshi, No. 210.

Ito, S. (1911). Ibid., No. 137.

Leong, P. C. (1940). J. Malaya Branch Brit. med. Ass., 4,66 .

Segawa, M. (1916). Zika-Zasshi, No. 189.

Toyoda, T. (1922). Zikken-Iho, 8, 88.

Wenckebach, K. F. (1935). The Beri-beri Heart (a summary in English by Tull, J. C.) Govt. Printing Office, Singapore.

Williams, C. D. (1938). J. Malaya Branch Brit. med. Ass., 2, 113. 